\title{
Long-Term Therapeutic Effect of Microvascular Decompression for Trigeminal Neuralgia: Kaplan-Meier Analysis in a Consecutive Series of 425 Patients
}

\author{
Yongxu WEI, Chunhua PU, Ning LI, Yu CAI, Hanbing SHANG, Weiguo ZHAO \\ Shanghai JiaoTong University, School of Medicine, Rui Jin Hospital, Department of Neurosurgery, Shanghai, China
}

\section{ABSTRACT}

AIM: To evaluate the long-term efficacy and safety of microvascular decompression (MVD) for treating trigeminal neuralgia (TN), and identify the predictors of pain relief.

MATERIAL and METHODS: A total of 425 patients who underwent surgery between 1991 and 2011 for idiopathic TN were included in this study. Pain outcome was graded using the Barrow Neurological Institute pain scale and success was defined as complete pain relief without medication. A Kaplan-Meier survival curve was generated. Univariate analysis and Cox proportional-hazards regression were performed to identify factors associated with the maintenance of long-term pain relief.

RESULTS: The cure rate was $89.3 \%$ at 1 year, $80.5 \%$ at 3 years, $75.6 \%$ at 5 years, and $71.2 \%$ at 8 years. Typical clinical presentation, arterial vessel compression, and age $\geq 60$ years at the time of surgery were independent predictors of an excellent outcome. Gender, side, branches involved, symptom duration, hypertension, previously failed surgery, and number of conflicted vessels had no prognostic value. A total of 36 patients $(8.47 \%)$ developed permanent cranial nerve injury and general complications and the mortality rate was $0.24 \%$.

CONCLUSION: MVD has positive effects for TN treatment, with persistent pain relief achieved in $71.2 \%$ of patients 8 years after the procedure. Long-term pain remission may be related to typical clinical presentation, an arterial conflicted vessel, and age $\geq 60$ years at the time of surgery.

KEYWORDS: Trigeminal neuralgia, Microvascular decompression, Outcome

\section{INTRODUCTION}

$\mathrm{T}$ Trigeminal neuralgia (TN) is characterized by unilateral, paroxysmal, lancinating, recurrent pain in one or more branches of the fifth cranial (trigeminal) nerve. It has an estimated incidence of 12.6 to 28.9 per 100,000 persons per year $(8,12,19)$. A blood vessel conflicted with the root entry zone (REZ) of the trigeminal nerve is believed to be a major contributing factor when there is no secondary cerebellopontine angle space-occupying lesion $(11,13,15)$.

Aggressive surgical treatment is considered when patients suffer breakthrough pain even at maximal doses of medication or cannot tolerate drug side effects. However, it is hard to choose among current widely accepted surgery options, including percutaneous rhizotomies (PR), stereotactic radiosurgery (SRS), and microvascular decompression (MVD) due to the difficulty of performing randomized controlled trials of these surgical techniques. Moreover, inconsistent criteria of facial pain relief were frequently used in different studies.

In our center, MVD has been routinely performed for intractable TN patient since 1991, and that provides us a rare opportunity to investigate the long-term efficacy of MVD in a large series. In addition, the potential prognostic factors related to the 
maintenance of persistent pain relief are also identified. The present study also followed the surgical trigeminal neuralgia scoring checklist (1), and the results could enhance comparability with other researches.

\section{MATERIAL and METHODS}

\section{Patient Population}

During the period from July 1991 to December 2011, the senior author (Zhao W) performed 539 MVDs for patients with idiopathic TN at the Department of Neurosurgery, RuiJin Hospital, Shanghai JiaoTong University School of Medicine (Shanghai, China). Of these patients, 49 were excluded due to a history of multiple sclerosis ( 3 patients), bilateral symptoms (16 patients), previous MVD (17 patients) or imprecise description about their pain characteristics (13 patients), 65 were excluded due to death of unrelated causes (8 patients) or insufficient follow-up records (57 patients). Finally, a total of 425 patients who had a failed drug management history were therefore enrolled in this study. All patients fulfilled the diagnostic criteria outlined by The International Classification of Headache Disorders, $3^{\text {rd }}$ edition (14). All aspects of this study were approved by the Rui Jin Clinic Institutional Review Board.

\section{Surgical Technique}

All operations were performed using a lateral suboccipital retrosigmoid approach as previously described in detail (22). After the dura was opened and the cerebrospinal fluid (CSF) was drained slowly, appropriate brain relaxation can be achieved with no retractor. Next, the entire trigeminal root was dissected free from the surrounding adhesive arachnoid membranes and examined from the REZ to the porus of Meckel's cave. Teflon was then implanted between the fifth nerve and all offending vessels. If no neurovascular conflict existed, only nerve combing was performed.

\section{Data Collection and Outcome Criteria}

Patient characteristics, pain properties, surgical findings, and operative results were recorded in a database while hospitalization. Pain outcomes and adverse effects related to the operation were first assessed through outpatient followup examinations, and later through yearly telephone surveys that was carried out by an investigator who was blinded to the patient's history and diagnosis (Wei Y). Typical TN was defined as characterized paroxysmal, electrical, shooting, or stabbing pain, and atypical TN was defined as episodic pain with intervals of persistent background facial pain. Outcome was assessed using the Barrow Neurological Institute pain scale (BNI) (7). Facial pain was considered as cured upon complete pain relief with no medications (BNI I II), and as failed when pain continued or recurred (BNI III V). Recurrence was defined as the return of facial pain to BNI grade IV and V after initial pain relief.

\section{Potential Predictors of Outcome}

The following potential prognostic factors were considered in the present study: (a) patient characteristics, including age at surgery, gender, hypertension, and previous failed surgery procedures other than MVD; (b) factors related to neuralgia, including the side involved, topography of the trigeminal nerve, symptom duration, and clinical presentation (typical vs. atypical); (c) factors related to intraoperative findings, such as arteries, veins, or mixed type, and number of conflicted vessels.

\section{Statistical Analysis}

Statistical analysis was performed with SPSS version 20.0 (SPSS Inc., Chicago, IL, USA) and GraphPad Prism 5.0 (GraphPad Software, Inc., La Jolla, CA, USA). Kaplan-Meier curves were calculated to determine the ratio of patients who responded to the operation. Correlations between prognostic factors and outcomes were assessed by Fisher's exact test, and further analyzed by Cox proportional-hazards regression. Results are shown as hazard ratios (HR) with $95 \%$ confidence intervals $(95 \% \mathrm{Cl})$.

\section{- RESULTS}

\section{Patient Characteristics}

Patient characteristics are shown in Table I. Among the 425 cases, $342(80.47 \%)$ had typical clinical presentation, 83 $(19.53 \%)$ presented with concomitant persistent facial pain between episodes, and most progressed from purely paroxysmal neuralgia over time. Hypertension was observed in 89 patients (20.94\%). Three hundred eighty-four patients $(90.35 \%)$ had clear neurovascular conflicts, arterial compression was seen in 310 patients (72.94\%); 27 (6.35\%) had pure venous compression, and $50(11.76 \%)$ had compression of both artery and vein, no compressed vessel was found in 41 patients $(9.6 \%)$. Of note, four female patients $(0.94 \%)$ had a family history of TN, with one or both parents affected.

\section{Facial Pain Outcome}

At the time of discharge, complete pain relief was seen in 396 patients $(93.18 \%)$, while the other 29 (6.82\%) experienced an inadequate reduction in facial pain; 62 (15.66\%) developed recurrent pain during the follow-up period (mean=8.9 years; range: $2.6-23$ years). Among the 91 failed cases (21.41\%), adequate pain control was eventually achieved in 39 by pharmacologic treatment, in 15 by additional SRS, and in 11 by PR, while 26 patients $(6.12 \%)$ experienced persistent facial pain even after various treatments. Since the length of the follow-up time varied between patients, long-term outcome was assessed by generating a Kaplan-Meier survival curve, at the 1-year follow-up evaluation, $89.3 \%$ of patients were cured; at 3,5 , and 8 years, $80.5 \%, 75.6 \%$, and $71.2 \%$ of patients were cured respectively (Figure 1).

\section{Prognostic Factors}

In the univariate analysis, patients who were older ( $\geq 60$ years), or had hypertension, typical clinical presentation, arterial compression, and a single offending vessel had significantly better outcome. However, Cox regression analysis suggested that only patients with typical symptoms ( $\mathrm{HR}=0.279,95 \%$ $\mathrm{Cl}$ : 0.173-0.451; $\mathrm{p}<0.0001$ ), pure arterial compression 
( $\mathrm{HR}=0.213,95 \% \mathrm{Cl}: 0.075-0.601 ; \mathrm{p}=0.004)$, or who were $\geq$ 60 years $(\mathrm{HR}=1.655,95 \% \mathrm{Cl}: 1.066-2.568 ; \mathrm{p}=0.025)$ had an excellent outcome (Table II, Figures 2,3, and 4).

\section{Complications}

Postoperatively developed permanent cranial nerve impairment and general surgery complications are listed in Table III. Persistent facial sensory dysfunction (facial numbness, hypoesthesia) was seen in 19 patients $(4.47 \%)$ while four $(0.94 \%)$ had hearing impairment. Wound infection, mostly minor, occurred in nine patients $(2.12 \%)$; two $(0.47 \%)$ had CSF leakage from the wound or rhinorrhea that required surgical repair. One patient $(0.24 \%)$ developed a bilateral frontal epidural hematoma immediately after the operation that was removed by emergency operation, after which the patient fully recovered. Another patient $(0.24 \%)$ developed delayed cerebellopontine angle hematoma, and died 5 days after the operation despite undergoing clearance by craniotomy. Hence, the mortality rate in this study was $0.24 \%$.

\section{DISCUSSION}

MVD is widely acknowledged as an effective method for TN treatment. However, alternative surgical methods such as PR and SRS also exist, and there is still no consensus regarding the most appropriate treatment.

The present study examined 425 consecutive patients who underwent MVD of the trigeminal nerve between 1991 and

Table I: Characteristics of This Series $(n=425)$

\begin{tabular}{lc}
\hline Characteristic & \\
\hline Median age (range), year & $60(23-86)$ \\
\hline Median pain duration (range), year & $5.0(0.1-30)$ \\
\hline Male/Female, $\mathrm{n}$ & $171 / 254$ \\
\hline Mean/Median follow-up, year & $8.9 / 7.2$ \\
\hline Left/Right, $\mathrm{n}$ & $186 / 239$ \\
\hline
\end{tabular}

Pain distribution, $\mathrm{n}(\%)$

Any $\mathrm{V} 1$ pain

$99(23.3 \%)$

Any V2 pain

$317(74.6 \%)$

Any V3 pain $245(57.6 \%)$

\begin{tabular}{lc}
\hline Prior surgery, yes/no, $\mathrm{n}$ & $61 / 364$ \\
\hline Hypertension, yes/no, $\mathrm{n}$ & $89 / 336$ \\
\hline TN type, Typical/Atypical, $\mathrm{n}$ & $342 / 83$ \\
\hline Intraoperative findings (\%) & \\
Any SCA & $266(62.6 \%)$ \\
Any Vein & $76(17.9 \%)$ \\
Both of artery and vein & $50(11.8 \%)$ \\
No compressing vessels & $41(9.6 \%)$ \\
\hline Family history, yes/no, $\mathrm{n}$ & $4 / 421$ \\
\hline
\end{tabular}

TN: Trigeminal neuralgia, SCA: Superior cerebellar artery, V1: Ophthalmic branch, V2: Maxillary branch, V3: Mandibular branch.

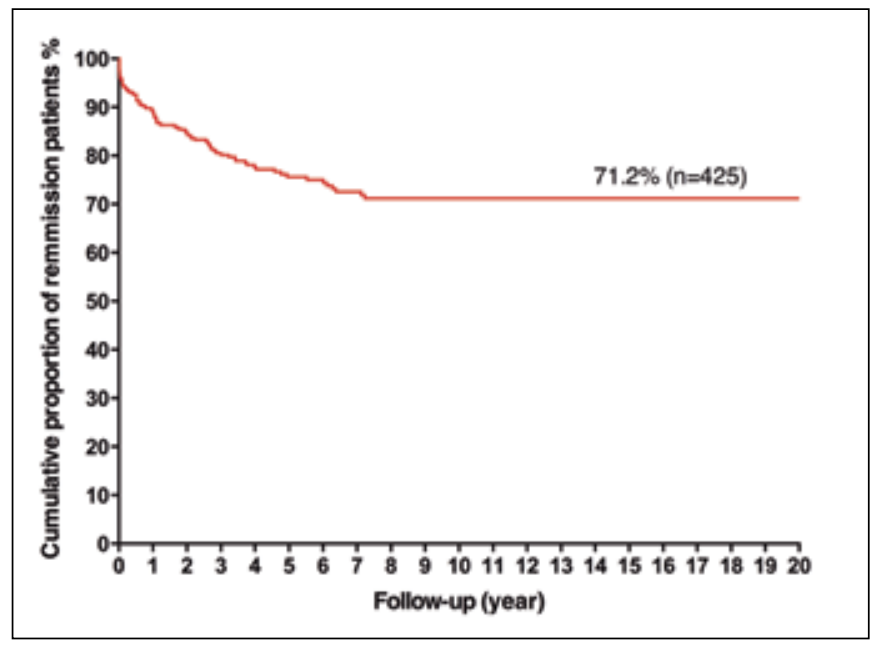

Figure 1: Long-term outcome of TN patients after MVD.

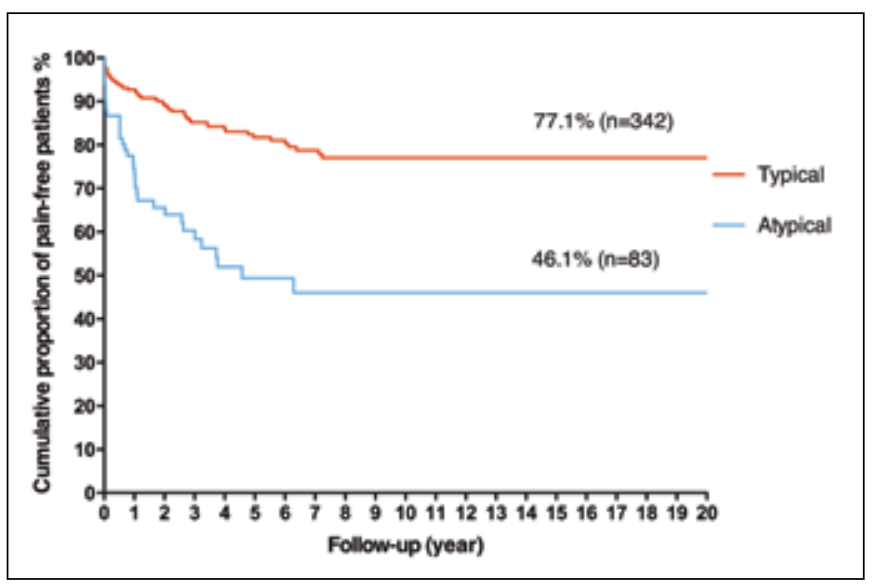

Figure 2: Kaplan-Meier curves of pain-free patients with typical or atypical presentation. A better outcome was observed in patients with typical rather than atypical presentation of facial pain after the operation $(\mathrm{HR}=0.279 ; \mathrm{p}<0.0001)$.

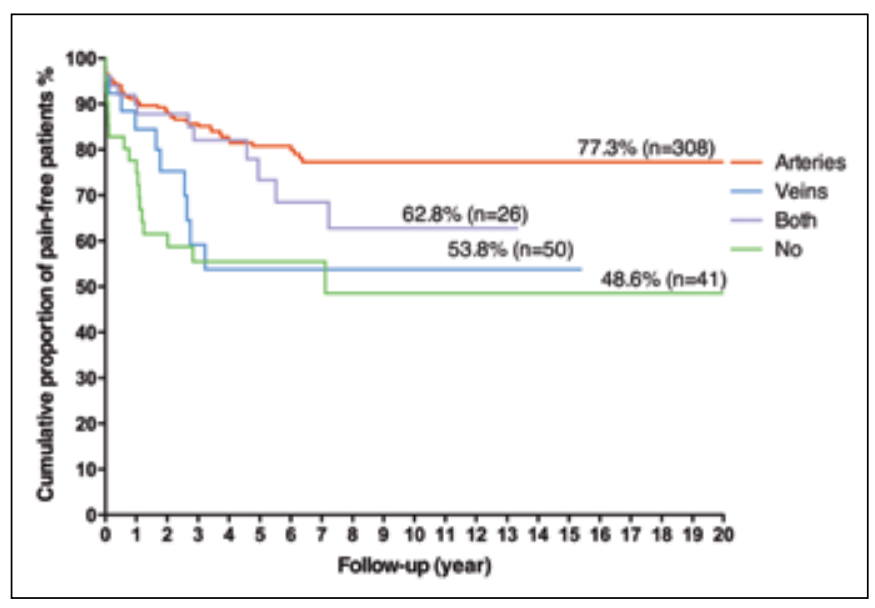

Figure 3: Patient prognosis with respect to conflicted vessel type. Patients with arterial compression had significantly better outcome $(\mathrm{HR}=0.213 ; \mathrm{p}=0.004)$ than those with venous or mixed compression or without clear neurovascular contact. 
Table II: Analysis of Factors Likely to Play a Role in Long-Term Outcome of Patients with TN after MVD

\begin{tabular}{|c|c|c|c|}
\hline Variables & Patients, n & $\mathbf{p}^{1}$ & $\mathbf{p}^{2}$ \\
\hline $\begin{array}{l}\text { Age } \\
\quad<60 / \geq 60 \text { year }\end{array}$ & $203 / 222$ & 0.025 & 0.025 \\
\hline $\begin{array}{l}\text { Sex } \\
\quad \text { Male/Female }\end{array}$ & $171 / 254$ & 0.187 & 0.096 \\
\hline $\begin{array}{l}\text { Side } \\
\text { Right/Left }\end{array}$ & 239/186 & 0.154 & 0.167 \\
\hline $\begin{array}{l}\text { Duration } \\
\qquad 1 \text { year } \\
\geq 1 \sim<\text { year } \\
\geq 8 \text { year }\end{array}$ & $\begin{array}{r}37 \\
233 \\
155 \\
\end{array}$ & 0.279 & 0.119 \\
\hline $\begin{array}{l}\text { TN type } \\
\quad \text { Typical/Atypical }\end{array}$ & $342 / 83$ & 0.000 & 0.000 \\
\hline $\begin{array}{l}\text { Pain distribution } \\
\text { V1 } \\
\text { V2 } \\
\text { V3 } \\
\text { V1 } 1+V 2 \\
V 2+V 3 \\
V 1+V 2+V 3\end{array}$ & $\begin{array}{r}11 \\
113 \\
97 \\
56 \\
116 \\
32\end{array}$ & 0.899 & 0.494 \\
\hline $\begin{array}{c}\text { Previous surgery } \\
\text { Yes/No }\end{array}$ & $61 / 364$ & 0.399 & 0.670 \\
\hline $\begin{array}{c}\text { Hypertension } \\
\text { Yes/No }\end{array}$ & $89 / 336$ & 0.042 & 0.074 \\
\hline $\begin{array}{l}\text { Compressing vessels } \\
\text { Arteries } \\
\text { Veins } \\
\text { Both } \\
\text { No }\end{array}$ & $\begin{array}{r}308 \\
26 \\
50 \\
41\end{array}$ & 0.000 & 0.004 \\
\hline $\begin{array}{c}\text { No. of vessels } \\
1 \\
>1 \\
0\end{array}$ & $\begin{array}{r}299 \\
85 \\
41\end{array}$ & 0.002 & 0.289 \\
\hline
\end{tabular}

TN: Trigeminal neuralgia, V1: Ophthalmic branch, V2: Maxillary branch, V3: Mandibular branch, $\boldsymbol{P}^{1}$ : $P$ value of Fisher's test, $\boldsymbol{P}^{2}: P$ value of Cox regression analysis.

Table III: Complications in Our Series $(n=425)$

\begin{tabular}{lc}
\hline Complications & Patient, $\mathbf{n}(\%)$ \\
\hline Permanent facial sensory dysfunction & $19(4.47)$ \\
\hline Wound infection & $9(2.12)$ \\
\hline Permanent hearing impairment & $4(0.94)$ \\
\hline CSF leak & $2(0.47)$ \\
\hline Cerebellopontine angle hematoma & $1(0.24)$ \\
\hline Epidural hematoma & $1(0.24)$ \\
\hline Total & $36(8.47)$
\end{tabular}

CSF: Cerebrospinal fluid.

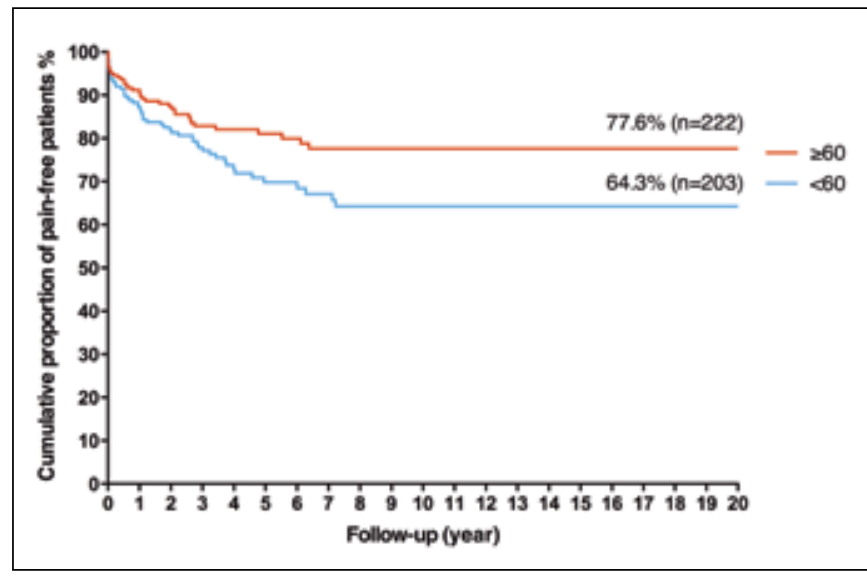

Figure 4: Patient outcomes with respect to age. Long-term outcome was better in older ( $\geq 60$ years) than in younger (<60years) patients $(H R=1.655 ; p=0.025)$.

2011. The Kaplan-Meier survival curve shows cured rates of $89.3 \%$ at 1 year, $80.5 \%$ at 3 years, and $71.2 \%$ at 8 years with a mean follow-up time of 8.9 years after MVD. These results are consistent with the reported range of $63 \%$ to $84 \%$ found in other studies $(22,26,28,32,40)$. In contrast, only $45.3 \%$ $66 \%$ of patients benefited from PR 5 years postoperatively $(5,17,25,30,38)$, and $34 \%-56 \%$ of patients experienced sustained pain relief 3 years after SRS $(10,21,31)$. Thus, patients who underwent MVD had the highest cured rate at follow-up as compared to those who were treated with other surgical methods.

Regarding the safety of the various surgical procedures, only MVD involves craniotomy. While the incidence of complications has decreased in recent years due to a refinement of the surgical technique, including the use of improved microscopes and precision instruments (40), permanent cranial injury and general complications related to the operation were seen in $8.47 \%$ of patients in this study, while the mortality rate was $2.4 \%$. A higher incidence of adverse effects associated with PR and SRS including temporary facial sensory dysfunction has been reported by many studies, but severe complications such as corneal perforation rarely occurred $(5,17,21,25,30,31,38)$. Moreover, there have been no reports of mortality resulting from PR or SRS interventions.

Interestingly, a recent study investigating the trends in surgical treatment for TN in the United States found that the number of MVD surgeries increased by nearly 200\% (from 842 to 2479) between 1998 and 2008 (39), while the incidence of PR decreased by $92 \%$ (from 1344 to 113) and that of SRS decreased by $80 \%$ in 2008 (from 730 to 149) after peaking in 2004. These changes in the surgical management of TN are likely due to further understanding of the advantages and risks of each surgical method.

Potential prognostic factors have been investigated in previous studies, including age at the time of surgery $(34,35)$, gender $(13,18,35)$, the side involved $(32,35)$, symptom duration $(2,4,18,20,34,35)$, previous failed surgical procedures $(2,6,33,35,36)$, topography of the trigeminal nerve $(24,32,35)$, 
clinical presentation $(23,24)$, and type of compressing vessel $(6,13,16)$. Here, the positive predictors of long-term outcome were older age ( $\geq 60$ years), typical clinical presentation, and arterial vascular compression. These findings may help surgeons in choosing more suitable MVD candidates.

The present data suggest that patients with typical TN tend to have a better outcome, consistent with most published results $(3,20,24,27,28,37,40)$, while an atypical clinical presentation did not have a negative impact on long-term outcome (32). This distinctive finding could be due in part to the study protocol, which excluded patients without offending vessels, and patients with no vessel compression were more likely to exhibit atypical pain symptoms and had worse outcomes than those with clear neurovascular conflicts (23).

Previous prognostic studies have suggested that the type of conflicted vessel observed intraoperatively affects long-term outcome after MVD, and arterial vascular compression was believed to be associated with a persistent pain-free state $(3,20)$. The same results were found in our study. The reason for this could be that arteries are more easily separated from the fifth nerve as compared to cases of venous or mixed contact. In the present cohort, patients with no visible neurovascular contact had the poorest outcome, despite the nerve combing performed.

Contrary to most studies, here, a better outcome was observed among older ( $\geq 60$ years) rather than younger patients. According to surgical records from our cases, more adequate nerve decompression can be achieved in older patients, since they were more likely to have a spacious corridor and higher prevalence of arteriosclerosis than younger patients. On the other hand, given a similar probability of recurrence, the exposure time is shorter in older patients, and they should therefore not be excluded from MVD if they are in good medical condition.

Unexpectedly, four female patients $(0.94 \%)$ had a family history of TN, with no multiple sclerosis, Charcot-Marie-Tooth neuropathy, or skull base abnormalities detected. All four cases had clear vascular compression, the outcome was excellent in three and poor in one case. Although there is ongoing debate about the best treatment approach $(9,29)$, the results of this study suggest that as for patients with idiopathic TN, familial TN cases can also benefit from MVD.

\section{CONCLUSION}

This study examined the long-term effectiveness and safety of MVD for idiopathic TN, and found pain relief that endured for at least 8 years in $71.2 \%$ of MVD cases. Statistically significant predictors for excellent long-term outcome are: Typical clinical presentation, arterial neurovascular compression, and older age ( $\geq 60$ years). Symptom duration and previous failed procedures had no effect on MVD prognosis. These findings should contribute to the appropriate selection of MVD candidates, while patients should also be informed about the efficiency and risks of alternative treatments to aid in decisionmaking.

\section{- REFERENCES}

1. Akram H, Mirza B, Kitchen N, Zakrzewska JM: Proposal for evaluating the quality of reports of surgical interventions in the treatment of trigeminal neuralgia: The surgical trigeminal neuralgia score. Neurosurg Focus 35:E3, 2013

2. Barba D, Alksne JF: Success of microvascular decompression with and without prior surgical therapy for trigeminal neuralgia. J Neurosurg 60:104-107, 1984

3. Barker FG 2nd, Jannetta PJ, Bissonette DJ, Larkins MV, Jho $\mathrm{HD}$ : The long-term outcome of microvascular decompression for trigeminal neuralgia. New Engl J Med 334:1077-1083, 1996

4. Bederson JB, Wilson CB: Evaluation of microvascular decompression and partial sensory rhizotomy in 252 cases of trigeminal neuralgia. J Neurosurg 71:359-367, 1989

5. Brown JA, McDaniel MD, Weaver MT: Percutaneous trigeminal nerve compression for treatment of trigeminal neuralgia: Results in 50 patients. Neurosurgery 32:570-573, 1993

6. Burchiel KJ, Clarke H, Haglund M, Loeser JD: Long-term efficacy of microvascular decompression in trigeminal neuralgia. J Neurosurg 69:35-38, 1988

7. Chen HI, Lee JY: The measurement of pain in patients with trigeminal neuralgia. Clin Neurosurg 57:129-133, 2010

8. Dieleman JP, Kerklaan J, Huygen FJ, Bouma PA, Sturkenboom MC: Incidence rates and treatment of neuropathic pain conditions in the general population. Pain 137:681-688, 2008

9. Fleetwood IG, Innes AM, Hansen SR, Steinberg GK: Familial trigeminal neuralgia. Case report and review of the literature. $J$ Neurosurg 95:513-517, 2001

10. Gronseth G, Cruccu G, Alksne J, Argoff C, Brainin M, Burchiel K, Nurmikko T, Zakrzewska JM: Practice parameter: The diagnostic evaluation and treatment of trigeminal neuralgia (an evidence-based review): Report of the Quality Standards Subcommittee of the American Academy of Neurology and the European Federation of Neurological Societies. Neurology 71:1183-1190, 2008

11. Haines SJ, Jannetta PJ, Zorub DS: Microvascular relations of the trigeminal nerve. An anatomical study with clinical correlation. J Neurosurg 52:381-386, 1980

12. Hall GC, Carroll D, Parry D, McQuay HJ: Epidemiology and treatment of neuropathic pain: The UK primary care perspective. Pain 122:156-162, 2006

13. Hamlyn PJ, King TT: Neurovascular compression in trigeminal neuralgia: A clinical and anatomical study. J Neurosurg 76:948-954, 1992

14. Headache Classification Committee of the International Headache S: The International Classification of Headache Disorders, 3rd ed. (beta version). Cephalalgia 33:629-808, 2013

15. Jannetta PJ: Arterial compression of the trigeminal nerve at the pons in patients with trigeminal neuralgia. J Neurosurg 26(1) Suppl:159-162, 1967

16. Jo KW, Kong DS, Hong KS, Lee JA, Park K: Long-term prognostic factors for microvascular decompression for trigeminal neuralgia. J Clin Neurosci 20:440-445, 2013 
Wei Y. et al: Microvascular Decompression for Trigeminal Neuralgia

17. Kanpolat Y, Savas A, Bekar A, Berk C: Percutaneous controlled radiofrequency trigeminal rhizotomy for the treatment of idiopathic trigeminal neuralgia: 25-year experience with 1,600 patients. Neurosurgery 48:524-532, 2001

18. Klun B: Microvascular decompression and partial sensory rhizotomy in the treatment of trigeminal neuralgia: Personal experience with 220 patients. Neurosurgery 30:49-52, 1992

19. Koopman JS, Dieleman JP, Huygen FJ, de Mos M, Martin CG, Sturkenboom MC: Incidence of facial pain in the general population. Pain 147:122-127, 2009

20. Li ST, Pan Q, Liu N, Shen F, Liu Z, Guan Y: Trigeminal neuralgia: What are the important factors for good operative outcomes with microvascular decompression. Surg Neurol 62:400-404, 2004

21. Maesawa S, Salame C, Flickinger JC, Pirris S, Kondziolka D, Lunsford LD: Clinical outcomes after stereotactic radiosurgery for idiopathic trigeminal neuralgia. J Neurosurg 94:14-20, 2001

22. McLaughlin MR, Jannetta PJ, Clyde BL, Subach BR, Comey $\mathrm{CH}$, Resnick DK: Microvascular decompression of cranial nerves: Lessons learned after 4400 operations. J Neurosurg 90:1-8, 1999

23. Miller JP, Acar F, Burchiel KJ: Classification of trigeminal neuralgia: Clinical, therapeutic, and prognostic implications in a series of 144 patients undergoing microvascular decompression. J Neurosurg 111:1231-1234, 2009

24. Miller JP, Magill ST, Acar F, Burchiel KJ: Predictors of long-term success after microvascular decompression for trigeminal neuralgia. J Neurosurg 110:620-626, 2009

25. North RB, Kidd DH, Piantadosi S, Carson BS: Percutaneous retrogasserian glycerol rhizotomy. Predictors of success and failure in treatment of trigeminal neuralgia. J Neurosurg 72:851-856, 1990

26. Oesman C, Mooij JJ: Long-term follow-up of microvascular decompression for trigeminal neuralgia. Skull Base 21:313322, 2011

27. Sandell T, Eide PK: Effect of microvascular decompression in trigeminal neuralgia patients with or without constant pain. Neurosurgery 63:93-99, 2008

28. Sarsam Z, Garcia-Finana M, Nurmikko TJ, Varma TR, Eldridge $\mathrm{P}$ : The long-term outcome of microvascular decompression for trigeminal neuralgia. Br J Neurosurg 24:18-25, 2010

29. Savica R, Lagana A, Siracusano R, Calabro RS, Ferlazzo E, Musolino R: Idiopathic familial trigeminal neuralgia: A case report. Neurol Sci 28:196-198, 2007
30. Scrivani SJ, Keith DA, Mathews ES, Kaban LB: Percutaneous stereotactic differential radiofrequency thermal rhizotomy for the treatment of trigeminal neuralgia. J Oral Maxillofac Surg 57:104-111, 1999

31. Sheehan J, Pan HC, Stroila M, Steiner L: Gamma knife surgery for trigeminal neuralgia: Outcomes and prognostic factors. J Neurosurg 102:434-441, 2005

32. Sindou M, Leston J, Decullier E, Chapuis F: Microvascular decompression for primary trigeminal neuralgia: Longterm effectiveness and prognostic factors in a series of 362 consecutive patients with clear-cut neurovascular conflicts who underwent pure decompression. J Neurosurg 107:11441153, 2007

33. Steiger HJ: Prognostic factors in the treatment of trigeminal neuralgia. Analysis of a differential therapeutic approach. Acta Neurochir 113:11-17, 1991

34. Sun T, Saito S, Nakai O, Ando T: Long-term results of microvascular decompression for trigeminal neuralgia with reference to probability of recurrence. Acta Neurochir 126:144-148, 1994

35. Theodosopoulos PV, Marco E, Applebury C, Lamborn $\mathrm{KR}$, Wilson CB: Predictive model for pain recurrence after posterior fossa surgery for trigeminal neuralgia. Arch Neurol 59:1297-1302, 2002

36. Tronnier VM, Rasche D, Hamer J, Kienle AL, Kunze S: Treatment of idiopathic trigeminal neuralgia: Comparison of long-term outcome after radiofrequency rhizotomy and microvascular decompression. Neurosurgery 48:1261-1267, 2001

37. Tyler-Kabara EC, Kassam AB, Horowitz MH, Urgo L, Hadjipanayis C, Levy El, Chang YF: Predictors of outcome in surgically managed patients with typical and atypical trigeminal neuralgia: Comparison of results following microvascular decompression. J Neurosurg 96:527-531, 2002

38. Udupi BP, Chouhan RS, Dash HH, Bithal PK, Prabhakar H: Comparative evaluation of percutaneous retrogasserian glycerol rhizolysis and radiofrequency thermocoagulation techniques in the management of trigeminal neuralgia. Neurosurgery 70:407-412, 2012

39. Wang DD, Ouyang D, Englot DJ, Rolston JD, Molinaro AM, Ward M, Chang EF: Trends in surgical treatment for trigeminal neuralgia in the United States of America from 1988 to 2008. J Clin Neurosci 20:1538-1545, 2013

40. Zhang H, Lei D, You C, Mao BY, Wu B, Fang Y: The long-term outcome predictors of pure microvascular decompression for primary trigeminal neuralgia. World Neurosurg 79:756-762, 2013 